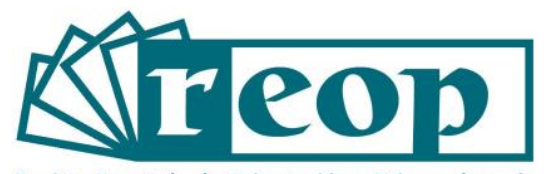

Revista Española de Orientación y Psicopedagogía

\title{
EDUCACIÓN INCLUSIVA: UNA REVISIÓN SISTEMÁTICA DE INVESTIGACIONES EN ESTUDIANTES, DOCENTES, FAMILIAS E INSTITUCIONES Y SUS IMPLICACIONES PARA LA ORIENTACIÓN EDUCATIVA $^{1}$
}

\section{INCLUSIVE EDUCATION: A SYSTEMATIC REVIEW OF RESEARCH IN STUDENTS, TEACHERS, FAMILIES AND INSTITUTIONS AND ITS IMPLICATIONS FOR EDUCATIONAL GUIDANCE}

\author{
Paola Andrea Reyes-Parra ${ }^{2}$ \\ Universidad de Boyacá. Facultad Ciencias Humanas y Educativas. Boyacá. Tunja, Colombia \\ Astrid Natalia Moreno Castiblanco \\ Universidad de Boyacá. Facultad Ciencias Humanas y Educativas. Boyacá. Tunja, Colombia \\ Angélica Amaya Ruiz \\ Universidad de Boyacá. Facultad Ciencias Humanas y Educativas. Boyacá. Tunja, Colombia \\ Mary Yolima Avendaño Angarita \\ Universidad de Boyacá. División de Bienestar Universitario. Boyacá. Tunja, Colombia
}

\section{RESUMEN}

La educación inclusiva se reconoce como un proceso para identificar y responder a la diversidad de los estudiantes y lograr mayor participación en la comunidad y en su aprendizaje. Este tema de gran interés para el ámbito de las ciencias humanas y educativas requiere de un análisis de los procesos de investigación realizados, y a partir de allí, generar estrategias innovadoras para implementar desde la orientación escolar y en el aula. El objetivo de esta revisión sistemática

1 Fuente de financiación: Grupo de Investigación ETHOS. Universidad de Boyacá.

${ }^{2}$ Correspondencia: Paola Andrea Reyes Parra. Correo-e: paolaa.reyesp@gmail.com, paoreyes@uniboyaca.edu.co 
sobre educación inclusiva, fue identificar las tendencias de trabajo con estudiantes, docentes, familias e instituciones. Se seleccionaron 50 artículos científicos en las bases de datos Psicodoc, Science Direct, APA PsycNET y EBSCOhost. Los resultados se presentan en cuatro categorías de análisis. En general, con estudiantes, se evidenció que se centran en comprender experiencias y mejorar el clima en el aula; con docentes, se identificó el análisis de prácticas pedagógicas y las necesidades de formación profesional; con familias, se observó que no se ha dado la suficiente profundidad a los procesos dentro del núcleo familiar; y a nivel institucional, es claro el interés por monitorear los procesos educativos y cumplimiento de políticas con el fin de mejorar las condiciones para el proceso de inclusión en todos los niveles de educación. En conclusión, aunque se evidencia el trabajo con diferentes actores educativos, se requiere mayor articulación entre ellos. En este sentido, los docentes y orientadores escolares pueden tomar la presente revisión como insumo para motivar la participación activa en la aplicación de herramientas pedagógicas, el fortalecimiento de prácticas familiares, la capacitación docente y la generación de políticas institucionales orientadas a la inclusión.

Palabras clave: Educación, inclusión, diversidad, orientación educativa, revisión sistemática

\begin{abstract}
Inclusive education is recognized as a process to identify and respond to the diversity of students and achieve greater participation in the community and in their learning. This topic of great interest to the field of Human and Educational Sciences, requires an analysis of the research processes carried out, in order to generate innovative strategies to be implemented in school guidance and within the classroom. The objective of this systematic review on inclusive education was to identify trends in working with students, teachers, families and institutions. 50 scientific articles were selected in Psicodoc, Science Direct, APA PsycNET y EBSCO. The results are presented in four categories of analysis. In general, with students, it was evident that they focus on understanding experiences and improving the climate in the classroom; with teachers, the analysis of pedagogical practices and professional training needs were identified; with families, it was observed that the processes within the family nucleus have not been given sufficient attention; and at the institutional level, there is a clear interest in monitoring educational processes and policy compliance in order to improve the conditions for inclusion at all levels of education. In conclusion, although the work with different educational actors is evident, greater articulation between them is required. In this sense, teachers and school counselors can take this review as an input to motivate active participation in the application of pedagogical tools, the strengthening of family practices, teacher training and the generation of institutional policies aimed at inclusion.
\end{abstract}

Key Words: Education, inclusion, diversity, educational orientation, systematic review.

\title{
Cómo citar este artículo:
}

Reyes-Parra, P. A., Moreno, A. N., Amaya, A. y Avendaño, M (2020). Educación inclusiva: Una revisión sistemática de investigaciones en estudiantes, docentes, familias e instituciones y sus implicaciones para la orientación educativa. Revista Española de Orientación y Psicopedagogía, 31(3), 86-108. https://doi.org/10.5944/reop.vol.31.num.3.2020.29263 


\section{Introducción}

La educación inclusiva ha tomado gran relevancia y se ha implementado en diferentes países y contextos educativos, ello implica el diseño y la implementación de estrategias que permitan garantizar una educación para todos y todas a partir de un trabajo mancomunado entre los diferentes actores del sistema educativo: estudiantes, docentes, directivos, familias, entre otros. La Organización de las Naciones Unidas para la Educación, la Ciencia y la Cultura (UNESCO) (2005), define la educación inclusiva como el proceso de identificar y responder a la diversidad de las necesidades de todos los educandos a través de una mayor participación en el aprendizaje, la cultura y la comunidad, para reducir la exclusión dentro y fuera del sistema educativo. En este sentido, se requiere reconocer, valorar y responder de manera pertinente a la diversidad de necesidades, habilidades, intereses, posibilidades y expectativas de los niños, niñas y adolescentes (NNA), garantizando en el marco de los derechos humanos, los ajustes razonables requeridos en su proceso educativo, a través de prácticas, políticas y culturas que eliminen las barreras existentes en el entorno educativo (MEN Colombia, 2017).

Hablar de diversidad en la escuela, es hablar de la participación de cualquier persona con independencia de sus características sociales, culturales, biológicas, intelectuales, afectivas, entre otras, reconociendo que la escuela es una comunidad, que debe fomentar el apoyo mutuo entre todos sus miembros (Booth y Ainscow, 2015). Es así como, para el caso específico de Colombia se establecen cinco grupos poblacionales en aras de garantizar su acceso, permanencia y/o graduación tales como: personas en situación de discapacidad y/o con talentos excepcionales; grupos étnicos (comunidades afrodescendientes, raizales y palenqueros, pueblos indígenas y pueblo Rom); población víctima del conflicto armado; población desmovilizada en proceso de reintegración; y habitantes de frontera (MEN, 2013 pp. 41-44). Desde esta perspectiva de inclusión se busca garantizar una educación para todos y todas, y por ende se deben desarrollar procesos con pertinencia, eficacia y calidad (UNESCO, 2009, p.9).

Para el logro de procesos inclusivos de calidad, se debe a) buscar una atención directa e indirecta de las necesidades de todo el estudiantado, lo cual implica reconocerlo como un sujeto único y diverso, y b) analizar la formación de los docentes para brindar una verdadera educación inclusiva y generar un vínculo entre la escuela y la familia, reconociendo que el primer paso para lograr una verdadera educación es el conocimiento del contexto en el cual está inmersa la institución. Es por esto, que surge la pregunta que orienta el desarrollo del presente estudio ¿Cuál ha sido la tendencia reciente en investigación sobre educación inclusiva? Responder a este interrogante, lograría un impacto a nivel académico y social, en la medida que permite a los entes educativos y personal implicado en procesos de educación inclusiva, conocer cómo se está abordando esta temática y así, llegar a la innovación en procesos tanto académicos como investigativos, con una gran implicación en el ámbito de la orientación y la psicopedagogía.

La revisión sistemática que se presenta permite a la comunidad académica, en especial a profesionales de la orientación educativa, vislumbrar los avances y retos en el área de la inclusión, para lo cual es fundamental el trabajo interdisciplinario y transdisciplinario. Como lo refieren Rojas et al. (2020) y Molina (2004), la labor del orientador escolar y la intervención psicopedagógica se sustenta en principios de prevención o atención a la diversidad del alumno, cuyos agentes educativos asumen la función de facilitar-promover su desarrollo integral para que se constituyan en seres transformadores de sí mismos y de su entorno. Es por esto que, dada la necesidad de comprender la complejidad de la educación inclusiva y la vinculación de la comunidad, el objetivo principal de la presente revisión sistemática, es identificar el abordaje que se está dando a la educación inclusiva, a la luz de investigaciones realizadas con estudiantes, docentes, familias y a nivel institucional, identificando en cada una de las categorías las tendencias y limitaciones que se 
presentan, de manera que se genere una actitud crítica reflexiva en el orientador, que pueda generar cambios para favorecer los procesos institucionales en pro de la diversidad.

\section{Método}

Se llevó a cabo una revisión sistemática de las bases de datos Psicodoc, Science Direct, APA PsycNET y EBSCOhost. Se revisaron estas bases por la calidad de las revistas y la relevancia para el ámbito de las ciencias humanas y educativas.

\section{Muestra}

La revisión sistemática se realizó con un total de 50 artículos, los cuales fueron seleccionados mediante búsqueda realizada a finales del año 2018. Se buscó la palabra clave educación inclusiva en las bases de datos Psicodoc, Science Direct, APA PsycNET y EBSCOhost.

\section{Procedimiento}

Se realizó la búsqueda de la palabra clave en castellano educación inclusiva en bases de datos científicas. Los criterios de selección de los documentos fueron los siguientes: publicados entre los años 2014 a 2018, artículos pertenecientes a las áreas de la educación y la psicología, textos completos empíricos, publicaciones open access.

Los criterios de exclusión de documentos fueron: estudios publicados en años fuera de la ventana de observación, artículos publicados en áreas de ciencias de la salud, estudios de revisión, teóricos o de reflexión y artículos restringidos. La Figura 1 evidencia el proceso de selección de artículos.

Una vez seleccionados los artículos, se diligenció una matriz la cual codificaba información básica de cada documento. Finalmente, se hizo la distribución de los estudios en las cuatro categorías de análisis (i.e. estudiantes, docentes, familias e institución), las cuales fueron definidas en función de la población objeto de estudio. 


\section{Figura 1}

Diagrama de flujo de la selección de artículos de la investigación

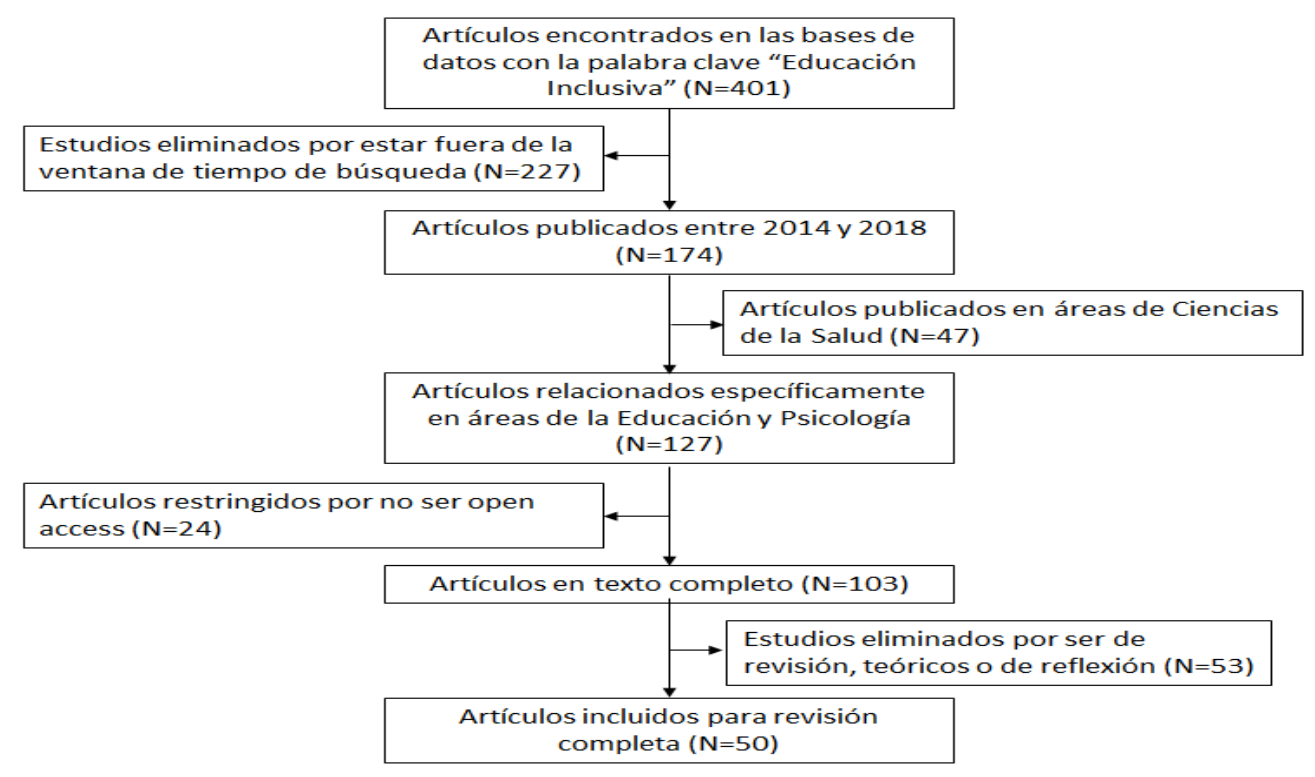

Fuente: Elaboración propia. Los cuadros hacia la izquierda y derecha presentan los criterios de exclusión para la selección de artículos.

\section{Instrumento}

La matriz de análisis construida contempló información básica de cada documento como: título de la investigación, autor, año de publicación, país de desarrollo, objetivo general, diseño de investigación, muestra y principales hallazgos. Para realizar el análisis de contenido, se contempló el universo de documentos seleccionados y se establecieron unidades de análisis correspondientes a la población objeto de estudio de cada artículo, el tema más recurrente y la metodología predominante. Las categorías generales fueron: a) artículos cuyo objeto de estudio se centra en historias de vida de estudiantes o sus experiencias en el aula en contextos escolares de educación preescolar, primaria, secundaria y algunos estudios dirigidos a la educación superior, b) en la categoría docente se profundiza en las diferentes percepciones, estrategias y prácticas de los profesores, c) tendencias en investigación sobre la relación que se establece entre la familia y, d) aspectos institucionales y políticas de educación inclusiva implementadas en la escuela.

\section{Resultados}

En total, se analizaron 50 artículos, los cuales, fueron realizados principalmente en países como España $(n=25)$, Colombia $(n=10)$ y Brasil $(n=5)$, seguido por Alemania, Estados Unidos, México $(n=2)$ y finalmente en Canadá, Chile, Reino Unido y Uruguay $(n=1)$. Con respecto al tipo de investigación privilegiado, se evidencia un predominio por metodologías cualitativas $(n=27)$ donde 3 de ellos se centran en un diseño de investigación-acción participativa. En cuanto a la 
investigación cuantitativa $(n=14)$ se evidencian estudios en su mayoría de tipo descriptivo, transversal y no experimental. Adicionalmente, se registraron 7 diseños mixtos y finalmente, tan solo se presentaron dos diseños instrumentales de validación de cuestionarios relacionados con la educación inclusiva. Ahora bien, con respecto al contenido y temáticas abordadas en los documentos, a continuación, se presentan los resultados para cada una de las categorías de análisis.

\section{Educación inclusiva - estudiantes}

Los artículos que constituyen el cuerpo base de estudio en la categoría educación inclusivaestudiantes, como se referencia en la TABLA 1, han sido desarrollados en las diversas etapas de educación con un mayor número de investigaciones científicas en educación secundaria, seguida por educación universitaria. Dos contextos en los cuales no se han desarrollado muchas investigaciones en torno a los procesos de educación inclusiva son a nivel de primaria y preescolar.

\section{Tabla 1}

Estudios categoría estudiantes

\begin{tabular}{|c|c|c|c|c|}
\hline Autor y Año & País & Objetivo & $\begin{array}{c}\text { Tipo de investigación } \\
\text { - Población }\end{array}$ & $\begin{array}{l}\text { Conclusiones } \\
\text { principales }\end{array}$ \\
\hline \multicolumn{5}{|c|}{ Estudiantes Preescolar } \\
\hline $\begin{array}{c}\text { Sekkel y Matos } \\
(2014)\end{array}$ & Brasil & $\begin{array}{l}\text { Conocer sobre la } \\
\text { formación de los } \\
\text { infantes en jardines } \\
\text { infantiles con } \\
\text { respecto a la } \\
\text { aceptación de las } \\
\text { diferencias. }\end{array}$ & $\begin{array}{c}\text { Cualitativo } \\
6 \text { infantes en edad } \\
\text { preescolar }\end{array}$ & $\begin{array}{l}\text { La educación infantil } \\
\text { inclusiva tiene papel } \\
\text { significativo en el } \\
\text { fortalecimiento de } \\
\text { experiencias } \\
\text { infantiles y mantienen } \\
\text { una abertura al otro } \\
\text { que permanece a lo } \\
\text { largo de la vida. }\end{array}$ \\
\hline $\begin{array}{c}\text { Cuevas et al. } \\
(2014)\end{array}$ & España & $\begin{array}{c}\text { Validar la } \\
\text { implementación de } \\
\text { una herramienta } \\
\text { para organizar y } \\
\text { estructurar el } \\
\text { diagnóstico de } \\
\text { infantes que viven } \\
\text { en condiciones de } \\
\text { riesgo. }\end{array}$ & $\begin{array}{c}\text { Cuantitativo } \\
63 \text { infantes en edad } \\
\text { preescolar }\end{array}$ & $\begin{array}{c}\text { Se ha visibilizado la } \\
\text { utilidad de una } \\
\text { herramienta } \\
\text { tecnológica para } \\
\text { organizar y } \\
\text { estructurar el } \\
\text { diagnóstico de } \\
\text { infantes que viven en } \\
\text { condiciones de } \\
\text { riesgo. }\end{array}$ \\
\hline $\begin{array}{c}\text { Gonzales y } \\
\text { Serrano (2016) }\end{array}$ & España & $\begin{array}{l}\text { Comprobar si el } \\
\text { clima de aula que } \\
\text { crea la metodología } \\
\text { de TP (trabajo por } \\
\text { proyectos) favorece } \\
\text { la inclusión } \\
\text { educativa. }\end{array}$ & $\begin{array}{c}\text { Cualitativo } \\
19 \text { estudiantes en } \\
\text { edad preescolar }\end{array}$ & $\begin{array}{c}\text { La diversidad es } \\
\text { entendida como algo } \\
\text { natural a la persona, y } \\
\text { que resulta } \\
\text { enriquecedora para las } \\
\text { relaciones en grupo; } \\
\text { no se considera como } \\
\text { un obstáculo. }\end{array}$ \\
\hline
\end{tabular}

Fuente: Elaboración propia 
Tabla 1 (Continuación)

Estudios categoría estudiantes

\begin{tabular}{|c|c|c|c|c|}
\hline Autor y Año & País & Objetivo & $\begin{array}{c}\text { Tipo de investigación } \\
\text { - Población }\end{array}$ & $\begin{array}{l}\text { Conclusiones } \\
\text { principales }\end{array}$ \\
\hline \multicolumn{5}{|c|}{ Estudiantes Primaria } \\
\hline $\begin{array}{c}\text { Gomes y Souza } \\
(2015)\end{array}$ & Brasil & $\begin{array}{c}\text { Comprender el } \\
\text { proceso de } \\
\text { subjetivación de una } \\
\text { estudiante de siete } \\
\text { años con } \\
\text { discapacidad física. }\end{array}$ & $\begin{array}{l}\text { Cualitativo } \\
1 \text { niña } \\
\text { de primaria }\end{array}$ & $\begin{array}{l}\text { La subjetividad se } \\
\text { forma a partir de la } \\
\text { negación de su } \\
\text { discapacidad y su } \\
\text { otredad, lo que indica } \\
\text { que su proceso } \\
\text { subjetivo de inclusión } \\
\text { se forma desde la } \\
\text { exclusión. }\end{array}$ \\
\hline $\begin{array}{c}\text { Palomares-Ruiz } \\
\text { et al. (2016) }\end{array}$ & España & $\begin{array}{c}\text { Analizar los } \\
\text { beneficios de la } \\
\text { Pedagogía } \\
\text { Hospitalaria en las } \\
\text { unidades de Salud } \\
\text { Mental que reciben } \\
\text { pacientes en edad } \\
\text { escolar que } \\
\text { permanecen largos } \\
\text { períodos ingresados. }\end{array}$ & $\begin{array}{c}\text { Mixto } \\
\text { Pacientes de } 11 \\
\text { años }\end{array}$ & $\begin{array}{c}\text { Es necesario } \\
\text { incrementar la } \\
\text { atención al alumnado } \\
\text { desde unas políticas } \\
\text { educativas y sanitarias } \\
\text { adecuadas. }\end{array}$ \\
\hline $\begin{array}{l}\text { Vesga et al. } \\
(2016)\end{array}$ & Colombia & $\begin{array}{l}\text { Comprender el } \\
\text { proceso de inclusión } \\
\text { escolar de una niña } \\
\text { con Parálisis } \\
\text { Cerebral del grado } \\
\text { tercero de básica } \\
\text { primaria de una } \\
\text { institución educativa. }\end{array}$ & $\begin{array}{l}\text { Cualitativo } \\
1 \text { estudiante } \\
\text { primaria }\end{array}$ & $\begin{array}{l}\text { La institución escolar } \\
\text { es un apoyo en el } \\
\text { proceso formativo y } \\
\text { personal de los niños, } \\
\text { especialmente en el } \\
\text { caso particular del } \\
\text { artículo }\end{array}$ \\
\hline $\begin{array}{c}\text { Acebes-de Pablo } \\
\text { y Carabias- } \\
\text { Galindo } \\
(2016)\end{array}$ & España & $\begin{array}{l}\text { Integrar niños con } \\
\text { TDAH en el } \\
\text { desarrollo de las } \\
\text { clases por medio de } \\
\text { la Musicoterapia. }\end{array}$ & $\begin{array}{c}\text { Mixto. } \\
2 \text { niños de tercer } \\
\text { grado de primaria con } \\
\text { TDAH }\end{array}$ & $\begin{array}{c}\text { La musicoterapia } \\
\text { mejora los síntomas } \\
\text { del trastorno y el nivel } \\
\text { de aprendizaje de los } \\
\text { sujetos. El docente } \\
\text { puede explorar esta } \\
\text { opción. }\end{array}$ \\
\hline $\begin{array}{l}\text { Powell et al. } \\
\quad(2016)\end{array}$ & $\begin{array}{l}\text { Estados } \\
\text { Unidos }\end{array}$ & $\begin{array}{l}\text { Entender el } \\
\text { razonamiento pre } \\
\text { algebraico de los } \\
\text { infantes en los } \\
\text { grados elementales } \\
\text { para diversificar las } \\
\text { estrategias } \\
\text { pedagógicas. }\end{array}$ & $\begin{array}{c}\text { Cuantitativo } \\
1.796 \text { estudiantes de } \\
1^{\circ} \text { y } 2^{\circ} \text { grado de } \\
\text { primaria }\end{array}$ & $\begin{array}{l}\text { Las expectativas pre } \\
\text { algebraicas para } \\
\text { infantes de primaria } \\
\text { han aumentado, por lo } \\
\text { que los docentes } \\
\text { deben mejorar las } \\
\text { habilidades aritméticas } \\
\text { en los niños. }\end{array}$ \\
\hline \multicolumn{5}{|c|}{ Estudiantes Preescolar } \\
\hline $\begin{array}{l}\text { Pastor et al. } \\
\quad(2016)\end{array}$ & España & $\begin{array}{c}\text { Construir la biografía } \\
\text { una persona que hub } \\
\text { vivido una situación } \\
\text { hándicap en la escue } \\
\text { analizarla desde cla } \\
\text { inclusivas. }\end{array}$ & $\begin{array}{l}\text { de } \\
\text { se } \\
\text { e } \\
\text { y }\end{array}$ & $\begin{array}{l}\text { Presenta un escenario } \\
\text { de reflexión sobre las } \\
\text { limitaciones y dificultades } \\
\text { que atraviesa una } \\
\text { persona que ha vivido } \\
\text { hándicap. }\end{array}$ \\
\hline
\end{tabular}

Fuente: Elaboración propia 
Tabla 1 (Continuación)

Estudios categoría estudiantes

\begin{tabular}{|c|c|c|c|c|}
\hline Autor y Año & País & Objetivo & $\begin{array}{l}\text { Tipo de } \\
\text { investigación } \\
\text { - Población }\end{array}$ & $\begin{array}{l}\text { Conclusiones } \\
\text { principales }\end{array}$ \\
\hline \multicolumn{5}{|c|}{ Estudiantes Secundaria } \\
\hline Rio et al. (2014) & España & $\begin{array}{l}\text { Analizar las diferencias en } \\
\text { las estrategias de } \\
\text { aprendizaje y patrones de } \\
\text { motivación manifestados } \\
\text { por estudiantes de } \\
\text { secundaria. }\end{array}$ & $\begin{array}{l}\text { Cuantitativo } \\
4337 \\
\text { Estudiantes } \\
\text { de secundaria }\end{array}$ & $\begin{array}{l}\text { Los planes inclusivos } \\
\text { refuerzan las } \\
\text { competencias } \\
\text { interculturales y de } \\
\text { aprender a aprender, } \\
\text { incluyendo la motivación. }\end{array}$ \\
\hline Márquez (2016) & España & $\begin{array}{l}\text { Comprender la presencia } \\
\text { de los procesos de fracaso } \\
\text { escolar como falta de } \\
\text { equidad en el entorno } \\
\text { educativo. }\end{array}$ & $\begin{array}{l}\text { Mixto } \\
11 \text { Institutos } \\
\text { de Educación } \\
\text { Secundaria }\end{array}$ & $\begin{array}{l}\text { Se hace imprescindible } \\
\text { que los centros } \\
\text { reflexionen sobre } \\
\text { prácticas discriminantes } \\
\text { y estrategias para lograr } \\
\text { la equidad. }\end{array}$ \\
\hline Monarca (2015) & España & $\begin{array}{l}\text { Comprender las políticas } \\
\text { de inclusión por los actores } \\
\text { de la comunidad educativa. }\end{array}$ & $\begin{array}{c}\text { Cualitativo } \\
15 \\
\text { estudiantes } \\
\text { de secundaria }\end{array}$ & $\begin{array}{l}\text { Cuando las políticas se } \\
\text { reducen a regulaciones } \\
\text { normativas, chocan } \\
\text { frontalmente con la } \\
\text { realidad y pasan a ser un } \\
\text { "elemento burocrático", } \\
\text { de escaso valor para las } \\
\text { regulaciones que } \\
\text { intentan dar algún tipo de } \\
\text { direccionalidad a la } \\
\text { realidad. }\end{array}$ \\
\hline $\begin{array}{c}\text { Schwarzenthal et } \\
\text { al. } \\
\text { (2018) }\end{array}$ & Alemania & $\begin{array}{l}\text { Efectos de } 2 \text { tipos de } \\
\text { normas de diversidad } \\
\text { cultural sobre la } \\
\text { discriminación percibida } \\
\text { entre estudiantes de origen } \\
\text { inmigrante y no inmigrante. }\end{array}$ & $\begin{array}{l}\text { Cuantitativo } \\
1.975 \\
\text { Estudiantes } \\
\text { de } \\
\text { secundaria, } \\
1213 \text { de } \\
\text { origen } \\
\text { inmigrante }\end{array}$ & $\begin{array}{l}\text { Los docentes tienen una } \\
\text { función importante en la } \\
\text { promoción de la } \\
\text { igualdad. }\end{array}$ \\
\hline $\begin{array}{l}\text { Hennig et al. } \\
\quad(2018)\end{array}$ & Alemania & $\begin{array}{l}\text { Evaluar las dificultades } \\
\text { vivenciadas por docentes, } \\
\text { padres y estudiantes con } \\
\text { Trastorno por déficit de } \\
\text { atención e hiperactividad } \\
\text { (TDAH) para establecer } \\
\text { relaciones. }\end{array}$ & $\begin{array}{l}\text { Cuantitativo } \\
114 \\
\text { estudiantes } \\
\text { de secundaria } \\
\text { con TDAH }\end{array}$ & $\begin{array}{l}\text { Los docentes tienden a } \\
\text { mantener creencias } \\
\text { pesimistas sobre las } \\
\text { habilidades académicas } \\
\text { y el éxito educativo } \\
\text { esperado de estudiantes } \\
\text { con TDAH. Se requiere } \\
\text { capacitación al } \\
\text { profesorado. }\end{array}$ \\
\hline \multicolumn{5}{|c|}{ Estudiantes Preescolar } \\
\hline $\begin{array}{l}\text { Bonilla y Jaimes } \\
\text { (2017) }\end{array}$ & Colombia & $\begin{array}{c}\text { Caracterizar las } \\
\text { representaciones sociales } \\
\text { de jóvenes pertenecientes } \\
\text { a 'parches' y pandillas de } \\
\text { una ciudad Colombiana, } \\
\text { frente al proceso de } \\
\text { educación inclusiva. }\end{array}$ & $\begin{array}{l}\text { Cualitativo } \\
30 \text { jóvenes de } \\
\text { secundaria }\end{array}$ & $\begin{array}{l}\text { Se ha evidenciado que } \\
\text { en el tema de pandillas } \\
\text { no existen espacios de } \\
\text { comprensión, } \\
\text { acercamiento, inclusión y } \\
\text { transformación. Se } \\
\text { requiere profundizar este } \\
\text { tipo de exclusión social. }\end{array}$ \\
\hline
\end{tabular}

Fuente: Elaboración propia 
Tabla 1 (Continuación)

Estudios categoría estudiantes

\begin{tabular}{|c|c|c|c|c|}
\hline Autor y Año & País & Objetivo & $\begin{array}{c}\text { Tipo de } \\
\text { investigación } \\
\text { - Población }\end{array}$ & $\begin{array}{l}\text { Conclusiones } \\
\text { principales }\end{array}$ \\
\hline \multicolumn{5}{|c|}{ Estudiantes Preescolar } \\
\hline Villac (2016) & Brasil & $\begin{array}{l}\text { Indagar la calidad de } \\
\text { servicio inclusivo ofrecido a } \\
\text { un estudiante con } \\
\text { discapacidad visual }\end{array}$ & $\begin{array}{l}\text { Cualitativo } \\
\text { Estudio de } \\
\text { caso }\end{array}$ & $\begin{array}{l}\text { La rutina escolar del } \\
\text { estudiante objeto de } \\
\text { estudio evidencia que } \\
\text { existen situaciones de } \\
\text { inclusión y exclusión. Las } \\
\text { faltas de un currículo } \\
\text { orientado a la } \\
\text { accesibilidad conducen a } \\
\text { la exclusión de } \\
\text { contenido. }\end{array}$ \\
\hline $\begin{array}{c}\text { Álvarez y } \\
\text { Chamorro (2017) }\end{array}$ & Colombia & $\begin{array}{c}\text { Mejorar el proceso de } \\
\text { enseñanza y aprendizaje } \\
\text { de los estudiantes de grado } \\
8^{\circ} \text { mediante la } \\
\text { incorporación del UDL en la } \\
\text { asignatura académica de } \\
\text { inglés. }\end{array}$ & $\begin{array}{c}\text { Cualitativo } \\
160 \\
\text { estudiantes }\end{array}$ & $\begin{array}{l}\text { Se presentan los } \\
\text { resultados del diseño } \\
\text { educativo creado } \\
\text { participativamente, para } \\
\text { dar solución a las } \\
\text { carencias } \\
\text { socioeducativas } \\
\text { identificadas. }\end{array}$ \\
\hline \multicolumn{5}{|c|}{ Estudiantes universitarios } \\
\hline $\begin{array}{l}\text { Barrios et al. } \\
\quad(2016)\end{array}$ & Colombia & $\begin{array}{c}\text { Analizar el nivel de } \\
\text { desarrollado de la } \\
\text { competencia intercultural } \\
\text { de estudiantes de } \\
\text { diferentes programas en } \\
\text { modalidad virtual de } \\
\text { aprendizaje. }\end{array}$ & $\begin{array}{l}\text { Mixto } \\
\quad 68 \\
\text { Estudiantes } \\
\text { universitario } \\
\text { de } \\
\text { asignaturas } \\
\text { virtuales }\end{array}$ & $\begin{array}{l}\text { Se consideran } \\
\text { competentes en el } \\
\text { desarrollo de la } \\
\text { comprensión y en el } \\
\text { respeto por las } \\
\text { diferencias y la } \\
\text { diversidad. }\end{array}$ \\
\hline $\begin{array}{c}\text { Moriña y Melero } \\
(2016)\end{array}$ & España & $\begin{array}{l}\text { Estudiar desde la } \\
\text { perspectiva del alumnado } \\
\text { con discapacidad, los } \\
\text { factores que contribuyen a } \\
\text { su éxito académico. }\end{array}$ & $\begin{array}{l}\text { Cualitativo } \\
44 \\
\text { Estudiantes } \\
\text { universitarios } \\
\text { con } \\
\text { discapacidad }\end{array}$ & $\begin{array}{l}\text { Se discute la importancia } \\
\text { de contar con sólidas } \\
\text { redes de apoyo para } \\
\text { contribuir a la inclusión } \\
\text { educativa y social. }\end{array}$ \\
\hline $\begin{array}{l}\text { Mirón Canelo et } \\
\text { al. (2018) }\end{array}$ & España & $\begin{array}{l}\text { Analizar una experiencia } \\
\text { desarrollada en un } \\
\text { programa de Medicina en } \\
\text { relación con la atención } \\
\text { integral a las personas con } \\
\text { discapacidad. }\end{array}$ & $\begin{array}{l}\text { Cuantitativo } \\
120 \\
\text { estudiantes } \\
\text { universitarios }\end{array}$ & $\begin{array}{l}\text { Los estudiantes de } \\
\text { medicina son } \\
\text { conscientes de su papel } \\
\text { social en la reducción de } \\
\text { desigualdades } \\
\text { relacionadas con la } \\
\text { salud. }\end{array}$ \\
\hline
\end{tabular}

Fuente: Elaboración propia

Con respecto a los contenidos de las investigaciones, se evidencia que, en su mayoría, se realizan procesos cualitativos para comprender cómo los estudiantes han experimentado algunas metodologías implementadas para contribuir a variables relacionadas con la convivencia (clima en el aula, aceptación de la diversidad cultural, representaciones sociales), procesos personales (motivación) y el desempeño académico (razonamiento algebraico, fracaso escolar, conocimiento de políticas en educación inclusiva). Así mismo, algunos de los estudios se centran en condiciones específicas de los estudiantes, y comparten historias de vida en casos de discapacidad física, TDAH, parálisis cerebral o trastornos mentales. 


\section{Educación inclusiva - docentes}

Los artículos que constituyen el cuerpo base de estudio para la categoría de educación inclusiva docente, como se evidencia en la TABLA 2, han sido desarrollados en las diversos niveles y ciclos de la educación: en primer lugar centrados en los futuros docentes (40\%), seguido del trabajo realizado por docentes en las instituciones educativas a nivel general (33.33\%); específicamente en instituciones de educación infantil y primaria (20\%); y finalmente en secundaria (6.6\%) donde se presentan pocas investigaciones al respecto.

\section{Tabla 2}

\section{Estudios categoría docentes}

\begin{tabular}{|c|c|c|c|c|}
\hline Autor y Año & País & Objetivo & $\begin{array}{c}\text { Tipo de Investigación } \\
\text { - Población }\end{array}$ & $\begin{array}{l}\text { Conclusiones } \\
\text { Principales }\end{array}$ \\
\hline \multicolumn{5}{|c|}{ Prácticas pedagógicas } \\
\hline $\begin{array}{l}\text { Aquino et al. } \\
\quad(2014)\end{array}$ & México & $\begin{array}{c}\text { Identificar estrategias } \\
\text { de apoyo en línea para } \\
\text { la atención a } \\
\text { estudiantes } \\
\text { universitarios con } \\
\text { discapacidad visual. }\end{array}$ & $\begin{array}{l}\text { Cualitativo - } \\
\text { Etnográfico. } \\
\text { Estudiantes con } \\
\text { discapacidad visual y } \\
\text { docentes }\end{array}$ & $\begin{array}{c}\text { La tiflotecnología es } \\
\text { una estrategia que } \\
\text { posibilita la } \\
\text { elaboración de } \\
\text { materiales y } \\
\text { entornos para } \\
\text { ciegos y débiles } \\
\text { visuales. }\end{array}$ \\
\hline $\begin{array}{l}\text { Álvarez y } \\
\text { López } \\
\text { (2015) }\end{array}$ & Colombia & $\begin{array}{c}\text { Analiza el rol del } \\
\text { profesorado en la } \\
\text { práctica de un enfoque } \\
\text { inclusivo de la } \\
\text { enseñanza. }\end{array}$ & $\begin{array}{l}\text { Descriptivo/ } \\
\text { Exploratorio no } \\
\text { experimental. } \\
111 \text { docentes } \\
\text { universitarios }\end{array}$ & $\begin{array}{l}\text { Existe la necesidad } \\
\text { de formar a los } \\
\text { docentes en } \\
\text { educación inclusiva, } \\
\text { metodologías, } \\
\text { adaptaciones, } \\
\text { estrategias } \\
\text { pedagógicas y } \\
\text { recursos didácticos. }\end{array}$ \\
\hline $\begin{array}{l}\text { Bunch } \\
\text { (2015) }\end{array}$ & Canadá & $\begin{array}{c}\text { Describir las estrategias } \\
\text { organizativas y } \\
\text { pedagógicas para } \\
\text { apoyar la inclusión de } \\
\text { todos los estudiantes } \\
\text { en aulas regulares. }\end{array}$ & $\begin{array}{c}\text { Cualitativo. } \\
4 \text { jurisdicciones } \\
\text { provinciales y } \\
\text { territoriales en Canadá }\end{array}$ & $\begin{array}{l}\text { Los docentes } \\
\text { necesitan un mayor } \\
\text { liderazgo en los } \\
\text { procesos de apoyo } \\
\text { a la educación } \\
\text { inclusiva para que } \\
\text { realmente se } \\
\text { promueva y } \\
\text { desarrolle. }\end{array}$ \\
\hline $\begin{array}{c}\text { Muntaner et } \\
\text { al. } \\
\text { (2015) }\end{array}$ & España & $\begin{array}{l}\text { Evaluar las sesiones de } \\
\text { aula cuya organización } \\
\text { se basa en los Grupos } \\
\text { Interactivos (Gl), para } \\
\text { determinar las variables } \\
\text { que aseguran que sean } \\
\text { prácticas inclusivas. }\end{array}$ & $\begin{array}{c}\text { Cualitativo. } \\
215 \text { alumnos y } 21 \\
\text { maestros del CEIP } \\
\text { Pintor Joan Miró de } \\
\text { Palma de Mallorca }\end{array}$ & $\begin{array}{c}\text { Los Grupos } \\
\text { Interactivos } \\
\text { favorecen la } \\
\text { inclusión educativa } \\
\text { y, por lo tanto, las } \\
\text { prácticas aumentan } \\
\text { la participación y el } \\
\text { aprendizaje de } \\
\text { todos }\end{array}$ \\
\hline
\end{tabular}

Fuente: Elaboración propia 
Tabla 2 (Continuación)

Estudios categoría docentes

\begin{tabular}{|c|c|c|c|c|}
\hline Autor y Año & País & Objetivo & $\begin{array}{c}\text { Tipo de } \\
\text { Investigación - } \\
\text { Población }\end{array}$ & $\begin{array}{l}\text { Conclusiones } \\
\text { Principales }\end{array}$ \\
\hline \multicolumn{5}{|c|}{ Prácticas pedagógicas } \\
\hline $\begin{array}{l}\text { Flores et al. } \\
\text { (2017) }\end{array}$ & México & $\begin{array}{l}\text { Identificar las prácticas } \\
\text { inclusivas de docentes } \\
\text { que forman docentes } \\
\text { en una Escuela Normal } \\
\text { en México. }\end{array}$ & $\begin{array}{l}\text { Cuantitativo. } \\
8 \text { docentes y } \\
247 \text { estudiantes }\end{array}$ & $\begin{array}{l}\text { Los docentes tienen } \\
\text { prácticas inclusivas, } \\
\text { apoyos en las condiciones } \\
\text { físicas del aula, } \\
\text { metodología y buena } \\
\text { relación maestro-alumno. } \\
\text { Se requiere un plan de } \\
\text { actualización docente que } \\
\text { propicie la implementación } \\
\text { de la educación inclusiva }\end{array}$ \\
\hline $\begin{array}{l}\text { Costa- } \\
\text { Renders } \\
(2017)\end{array}$ & Brasil & $\begin{array}{l}\text { Analizar las prácticas } \\
\text { inclusivas desarrolladas } \\
\text { en la Universidad } \\
\text { Metodista de São } \\
\text { Paulo, entre los años } \\
\text { de } 2005 \text { y } 2010 .\end{array}$ & $\begin{array}{l}\text { Investigación } \\
\text { Participante. } \\
\text { Estudiantes y } \\
\text { docentes de } \\
\text { Universidad } \\
\text { entre } 2005 \text { y } \\
2010 .\end{array}$ & $\begin{array}{l}\text { Los docentes necesitan } \\
\text { aprender nuevas } \\
\text { estrategias de enseñanza. }\end{array}$ \\
\hline $\begin{array}{l}\text { Zwerg- } \\
\text { Villegas y } \\
\text { Jiménez } \\
(2015)\end{array}$ & Colombia & $\begin{array}{c}\text { Analizar la } \\
\text { discriminación y } \\
\text { exclusión laboral } \\
\text { enfrentada por } \\
\text { graduados } \\
\text { universitarios } \\
\text { provenientes de clases } \\
\text { socioeconómicas } \\
\text { bajas. }\end{array}$ & $\begin{array}{l}\text { Cuantitativo } \\
708 \text { decanos y } \\
\text { directivos } \\
\text { docentes }\end{array}$ & $\begin{array}{l}\text { Los directivos de } \\
\text { universidades privadas y } \\
\text { públicas perciben la } \\
\text { discriminación de manera } \\
\text { similar. Sin embargo, las } \\
\text { instituciones privadas } \\
\text { advierten mayor } \\
\text { responsabilidad en } \\
\text { remediarla y las públicas } \\
\text { menor responsabilidad de } \\
\text { contrarrestarla. }\end{array}$ \\
\hline $\begin{array}{l}\text { Nadal et al. } \\
(2016)\end{array}$ & España & $\begin{array}{c}\text { Analizar el } \\
\text { funcionamiento y la } \\
\text { organización de los } \\
\text { sistemas de apoyo de } \\
\text { centros de Educación } \\
\text { Infantil y Primaria de la } \\
\text { Comunidad } \\
\text { Valenciana. }\end{array}$ & $\begin{array}{c}\text { Cualitativo } \\
24 \text { profesionales }\end{array}$ & $\begin{array}{c}\text { A pesar de que se } \\
\text { observa un cierto avance } \\
\text { en el modelo de apoyo, } \\
\text { todavía existe una } \\
\text { concepción tradicional } \\
\text { centrada en el alumnado. }\end{array}$ \\
\hline \multicolumn{5}{|c|}{ Aspectos personales del docente } \\
\hline $\begin{array}{l}\text { Vigo et al. } \\
(2016)\end{array}$ & España & $\begin{array}{l}\text { Conocer las } \\
\text { percepciones del } \\
\text { profesorado sobre las } \\
\text { relaciones familia- } \\
\text { escuela inclusiva }\end{array}$ & $\begin{array}{c}\text { Etnográfica. } \\
8 \text { centros de la } \\
\text { comunidad } \\
\text { Autónoma de } \\
\text { Aragón (España) } \\
\text { de educación } \\
\text { primaria, } \\
\text { secundaria, } \\
\text { pública y } \\
\text { concertada, rural } \\
\text { y urbana. }\end{array}$ & $\begin{array}{l}\text { Conocer las familias de } \\
\text { los educandos es } \\
\text { primordial para los } \\
\text { docentes, porque a partir } \\
\text { de allí, se hacen } \\
\text { conscientes del contexto } \\
\text { del alumnado. }\end{array}$ \\
\hline
\end{tabular}


Tabla 2 (Continuación)

Estudios categoría docentes

\begin{tabular}{|c|c|c|c|c|}
\hline Autor y Año & País & Objetivo & $\begin{array}{c}\text { Tipo de } \\
\text { Investigación - } \\
\text { Población }\end{array}$ & $\begin{array}{l}\text { Conclusiones } \\
\text { Principales }\end{array}$ \\
\hline \multicolumn{5}{|c|}{ Aspectos personales del docente } \\
\hline $\begin{array}{c}\text { Kershner } \\
(2016)\end{array}$ & $\begin{array}{l}\text { Reino } \\
\text { Unido }\end{array}$ & $\begin{array}{l}\text { Establecer la relación } \\
\text { entre inclusión } \\
\text { educativa, diálogo y } \\
\text { psicología }\end{array}$ & $\begin{array}{l}\text { Cualitativo. } \\
8 \text { profesores en } \\
\text { sus primeros } \\
\text { años de ejercicio } \\
\text { docente }\end{array}$ & $\begin{array}{c}\text { Existe una relación entre } \\
\text { pensamiento psicológico, } \\
\text { prácticas de aula, } \\
\text { derechos del niño e } \\
\text { identidades sociales. }\end{array}$ \\
\hline $\begin{array}{l}\text { Angenscheidt } \\
\text { y Navarrete } \\
(2017)\end{array}$ & Uruguay & $\begin{array}{l}\text { Describir las actitudes } \\
\text { de los docentes de } \\
\text { enseñanza inicial y } \\
\text { primaria sobre la } \\
\text { educación inclusiva. }\end{array}$ & $\begin{array}{l}\text { Cuantitativo, de } \\
\text { tipo transversal y } \\
\text { descriptivo. } \\
44 \text { docentes de } \\
\text { un Colegio } \\
\text { Privado de } \\
\text { Montevideo, de } \\
\text { las áreas de } \\
\text { Inglés y Español. }\end{array}$ & $\begin{array}{l}\text { Los docentes tienen una } \\
\text { actitud favorable hacia los } \\
\text { fundamentos y prácticas } \\
\text { de la educación inclusiva. } \\
\text { Así mismo, los docentes } \\
\text { con más experiencia } \\
\text { tienen una actitud más } \\
\text { favorable en relación con } \\
\text { las medidas y prácticas } \\
\text { inclusivas. }\end{array}$ \\
\hline $\begin{array}{c}\text { Nikleva y } \\
\text { Rico-Martín } \\
(2017)\end{array}$ & España & $\begin{array}{l}\text { Identificar las actitudes } \\
\text { predominantes y } \\
\text { estereotipos culturales } \\
\text { hacia los inmigrantes } \\
\text { en España entre los } \\
\text { futuros profesores. }\end{array}$ & $\begin{array}{l}\text { Descriptivo. } \\
151 \text { estudiantes } \\
\text { en el grado de } \\
\text { Educación } \\
\text { Primaria en la } \\
\text { Universidad de } \\
\text { Granada. }\end{array}$ & $\begin{array}{l}\text { Es necesario fortalecer } \\
\text { en los docentes el } \\
\text { reconocimiento por los } \\
\text { principios de la educación } \\
\text { inclusiva y generar } \\
\text { empatía. }\end{array}$ \\
\hline $\begin{array}{l}\text { Jiménez Ruíz } \\
\text { et al. (2018) }\end{array}$ & España & $\begin{array}{l}\text { Analizar los discursos } \\
\text { en torno a la } \\
\text { conceptualización de la } \\
\text { Educación Inclusiva }\end{array}$ & $\begin{array}{l}\text { Cualitativo. } \\
85 \text { profesionales } \\
\text { (directores, } \\
\text { profesores, } \\
\text { terapeutas y } \\
\text { tutores de aula) }\end{array}$ & $\begin{array}{l}\text { Los docentes tienen } \\
\text { actitud positiva hacia la } \\
\text { inclusión, pero no cuentan } \\
\text { con la formación } \\
\text { suficiente, recursos y } \\
\text { apoyos para una } \\
\text { adecuada atención. } \\
\text { Persiste la idea de } \\
\text { necesitar un apoyo } \\
\text { educativo por parte de } \\
\text { especialistas. }\end{array}$ \\
\hline \multicolumn{5}{|c|}{ Formación de docentes } \\
\hline $\begin{array}{l}\text { Louzada et al. } \\
\text { (2015) }\end{array}$ & Brasil & $\begin{array}{l}\text { Analizar la oferta de } \\
\text { disciplinas sobre la } \\
\text { formación de } \\
\text { profesores en la } \\
\text { perspectiva de la } \\
\text { educación inclusiva. }\end{array}$ & $\begin{array}{c}\text { Mixto. } \\
104 \text { cursos de } \\
\text { licenciaturas } \\
\text { ofrecidos por } 3 \\
\text { Instituciones de } \\
\text { Educación } \\
\text { Superior de } \\
\text { Brasil. }\end{array}$ & $\begin{array}{c}\text { Las disciplinas } \\
\text { relacionadas con la } \\
\text { educación inclusiva están } \\
\text { en mayor número en las } \\
\text { humanidades. Debe } \\
\text { existir capacitación en } \\
\text { legislación, didácticas y } \\
\text { pedagogías con un } \\
\text { trabajo interdisciplinario. }\end{array}$ \\
\hline
\end{tabular}

Fuente: Elaboración propia 
Tabla 2 (Continuación)

Estudios categoría docentes

\begin{tabular}{|c|c|c|c|c|}
\hline Autor y Año & País & Objetivo & $\begin{array}{c}\text { Tipo de } \\
\text { Investigación - } \\
\text { Población }\end{array}$ & $\begin{array}{l}\text { Conclusiones } \\
\text { Principales }\end{array}$ \\
\hline \multicolumn{5}{|c|}{ Formación de docentes } \\
\hline $\begin{array}{l}\text { Pegalajar y } \\
\text { Colmenero } \\
(2017)\end{array}$ & España & $\begin{array}{c}\text { Analizar las actitudes y } \\
\text { necesidades formativas } \\
\text { hacia la inclusión del } \\
\text { docente de Educación } \\
\text { Secundaria Obligatoria } \\
\text { (ESO) }\end{array}$ & $\begin{array}{c}\text { Descriptivo. } \\
407 \text { docentes que } \\
\text { impartieron clase } \\
\text { en la etapa de } \\
\text { ESO de la } \\
\text { provincia de Jaén } \\
\text { durante el curso } \\
2010-2011\end{array}$ & $\begin{array}{l}\text { Los docentes consideran } \\
\text { la atención a la diversidad } \\
\text { como un deber de la } \\
\text { escuela y del sistema } \\
\text { educativo, incluyéndolo } \\
\text { en su práctica diaria. Sin } \\
\text { embargo, manifiestan que } \\
\text { los conocimientos sobre } \\
\text { educación inclusiva } \\
\text { adquiridos durante su } \\
\text { proceso de formación } \\
\text { inicial son muy pocos. }\end{array}$ \\
\hline $\begin{array}{l}\text { De la Rosa } \\
\text { (2017) }\end{array}$ & España & $\begin{array}{c}\text { Mejorar las } \\
\text { competencias del } \\
\text { docente en formación } \\
\text { de la Universidad de } \\
\text { Málaga }\end{array}$ & $\begin{array}{l}\text { Cualitativo. } \\
6 \text { alumnos }\end{array}$ & $\begin{array}{l}\text { Es importante generar en } \\
\text { las aulas inclusivas, } \\
\text { momentos para el } \\
\text { aprendizaje dialógico, la } \\
\text { interacción, y el } \\
\text { fortalecimiento de } \\
\text { aspectos socio-afectivos. }\end{array}$ \\
\hline $\begin{array}{c}\text { Yupanqui- } \\
\text { Concha et al. } \\
(2014)\end{array}$ & Chile & $\begin{array}{l}\text { Describir la percepción } \\
\text { de los actores clave en } \\
\text { el proceso educativo } \\
\text { sobre el impacto de } \\
\text { una intervención de } \\
\text { educación inclusiva }\end{array}$ & $\begin{array}{c}\text { Mixto } \\
15 \\
\text { establecimientos } \\
\text { educativos }\end{array}$ & $\begin{array}{l}\text { El Terapeuta Ocupacional } \\
\text { aporta considerablemente } \\
\text { a la inclusión de niños y } \\
\text { niñas con discapacidad, } \\
\text { por lo que es importante } \\
\text { incorporar estas } \\
\text { temáticas en la formación } \\
\text { profesional. }\end{array}$ \\
\hline
\end{tabular}

Fuente: Elaboración propia

Las temáticas trabajadas en la categoría docente se podrían dividir en tres aspectos específicos. En primer lugar, sobresale el trabajo realizado en torno a la identificación de estrategias pedagógicas implementadas por los docentes en el aula, además de su rol y las prácticas inclusivas realizadas mediante el apoyo y diálogo con sus estudiantes. En segundo lugar, se profundiza específicamente en el docente, su percepción, actitud, estereotipos y conocimiento de la educación inclusiva. Finalmente, en tercer lugar, se centran en estudios sobre la necesidad de formación en los docentes y las competencias potenciales que deben ser desarrolladas en el marco de su profesión.

\section{Educación inclusiva - familia}

La tercera categoría de análisis relaciona las tendencias en investigación sobre la vinculación de la familia a la escuela en pro de garantizar procesos educativos inclusivos. Se evidencia que sólo hacen hincapié en los procesos de adaptación a la escuela, experiencias de comunicación 0 percepción de familias frente al proceso inclusivo. La TABLA 3 presenta los diferentes aspectos relevantes de las investigaciones. 


\section{Tabla 3}

Estudios categoría familia

\begin{tabular}{|c|c|c|c|c|}
\hline Autor y Año & País & Objetivo & $\begin{array}{c}\text { Tipo de investigación } \\
\text { - Población }\end{array}$ & $\begin{array}{l}\text { Conclusiones } \\
\text { principales }\end{array}$ \\
\hline $\begin{array}{l}\text { Vera et al. } \\
\quad(2014)\end{array}$ & Colombia & $\begin{array}{l}\text { Comprender la } \\
\text { situación de una } \\
\text { comunidad escolar al } \\
\text { recibir a población } \\
\text { víctima de violencia } \\
\text { política y analizar si la } \\
\text { respuesta educativa } \\
\text { favorece su inclusión. }\end{array}$ & $\begin{array}{c}\text { Cualitativa } \\
25 \text { entrevistas a } \\
\text { docentes, directivos, } \\
\text { padres y niños } \\
\text { desplazados y no } \\
\text { desplazados }\end{array}$ & $\begin{array}{l}\text { Las conclusiones } \\
\text { muestran las } \\
\text { dificultades y } \\
\text { tensiones de la } \\
\text { escuela para } \\
\text { adaptarse a las } \\
\text { nuevas lógicas } \\
\text { sociales y para } \\
\text { favorecer una } \\
\text { respuesta inclusiva. }\end{array}$ \\
\hline $\begin{array}{l}\text { Martínez- } \\
\text { Figueira et al. } \\
(2016)\end{array}$ & España & $\begin{array}{c}\text { Interpretar la } \\
\text { percepción que las } \\
\text { familias con hijos e } \\
\text { hijas con Necesidades } \\
\text { Específicas de Apoyo } \\
\text { Educativo tienen en } \\
\text { torno a la conciliación } \\
\text { de sus tiempos } \\
\text { cotidianos. }\end{array}$ & $\begin{array}{c}\text { Mixto } \\
127 \text { familias }\end{array}$ & $\begin{array}{c}\text { Es necesaria la } \\
\text { corresponsabilidad } \\
\text { familiar en el proceso } \\
\text { de enseñanza- } \\
\text { aprendizaje de sus } \\
\text { hijos, aunque se } \\
\text { evidencia la dificultad } \\
\text { para conciliar tiempos } \\
\text { en sus trabajos que } \\
\text { les permita mayor } \\
\text { acompañamiento en } \\
\text { las instituciones. }\end{array}$ \\
\hline $\begin{array}{l}\text { Hernández et al. } \\
(2016)\end{array}$ & España & $\begin{array}{l}\text { Establecer lazos de } \\
\text { comunicación y } \\
\text { colaboración mutua } \\
\text { entre las familias de } \\
\text { los escolares y los } \\
\text { centros educativos } \\
\text { para el desarrollo de la } \\
\text { educación integral del } \\
\text { alumnado. }\end{array}$ & $\begin{array}{l}\text { Cuantitativo } \\
2494 \text { familias }\end{array}$ & $\begin{array}{l}\text { Los padres y madres } \\
\text { españoles conocen y } \\
\text { participan en procesos } \\
\text { educativos de sus } \\
\text { hijos, contribuyendo al } \\
\text { desarrollo del } \\
\text { aprendizaje del } \\
\text { alumnado desde el } \\
\text { hogar. }\end{array}$ \\
\hline
\end{tabular}

Fuente: Elaboración propia

\section{Educación inclusiva - nivel institucional}

La cuarta categoría de análisis se estableció por la importancia que reviste el trabajo a nivel institucional como estrategia de garantizar la educación para todos y todas. La TABLA 4 presenta las publicaciones seleccionadas, en la cual se evidencia que predominan estudios orientados a la evaluación institucional, para identificar fortalezas y oportunidades de mejora en los procesos inclusivos y proyectos pedagógicos. Así mismo, en esta categoría se resaltan dos estudios instrumentales, los cuales se basan en el diseño y validación de cuestionarios que permitan realizar un monitoreo de la presencia de condiciones óptimas a nivel institucional para la inclusión. 


\section{Tabla 4}

Estudios categoría Institucional

\begin{tabular}{|c|c|c|c|c|}
\hline Autor y Año & País & Objetivo & $\begin{array}{l}\text { Tipo de } \\
\text { investigación - } \\
\text { Población }\end{array}$ & $\begin{array}{l}\text { Conclusiones } \\
\text { principales }\end{array}$ \\
\hline \multicolumn{5}{|c|}{ Evaluación institucional } \\
\hline $\begin{array}{l}\text { Arnaiz et al. } \\
(2015)\end{array}$ & España & $\begin{array}{c}\text { Analizar las fortalezas y } \\
\text { las barreras presentes } \\
\text { en cuatro centros de } \\
\text { Educación Infantil y } \\
\text { Primaria de la Región de } \\
\text { Murcia para el desarrollo } \\
\text { de una Educación } \\
\text { Inclusiva. }\end{array}$ & $\begin{array}{l}\text { Cuantitativa } \\
4 \text { centros de } \\
\text { Educación } \\
\text { Infantil y } \\
\text { Primaria de la } \\
\text { Región de } \\
\text { Murcia }\end{array}$ & $\begin{array}{l}\text { Las principales debilidades } \\
\text { radican en la organización } \\
\text { de la acción tutorial, el } \\
\text { respeto a los ritmos y } \\
\text { características individuales } \\
\text { del alumnado, las } \\
\text { relaciones centro-contexto- } \\
\text { social y la implicación } \\
\text { activa del alumnado en su } \\
\text { propio aprendizaje. }\end{array}$ \\
\hline $\begin{array}{l}\text { Beltrán et al. } \\
\text { (2015) }\end{array}$ & Colombia & $\begin{array}{l}\text { Articular el esfuerzo de } \\
\text { diferentes actores de la } \\
\text { comunidad educativa } \\
\text { mediante "comunidades } \\
\text { de aprendizaje". }\end{array}$ & $\begin{array}{l}\text { Investigación- } \\
\text { Acción } \\
30 \text { docentes, } \\
837 \text { estudiantes } \\
\text { de primaria y } \\
\text { secundaria. }\end{array}$ & $\begin{array}{l}\text { Las estrategias utilizadas } \\
\text { permitieron identificar las } \\
\text { principales necesidades en } \\
\text { la institución, propiciar un } \\
\text { proceso participativo y } \\
\text { fortalecer la relación entre } \\
\text { el saber cultural de toda } \\
\text { la comunidad y el saber } \\
\text { académico. }\end{array}$ \\
\hline $\begin{array}{l}\text { Parrilla y Sierra } \\
\text { (2015) }\end{array}$ & España & $\begin{array}{l}\text { Sensibilizar a la } \\
\text { comunidad social y } \\
\text { educativa sobre la } \\
\text { importancia inclusiva o } \\
\text { por el contrario } \\
\text { excluyente que pueden } \\
\text { suponer los momentos y } \\
\text { periodos de transición } \\
\text { educativa. }\end{array}$ & $\begin{array}{l}\text { Investigación } \\
\text { Acción } \\
\text { Participativa } \\
9 \text { centros } \\
\text { escolares }\end{array}$ & $\begin{array}{l}\text { El estudio propone algunas } \\
\text { prácticas que podrían } \\
\text { plantearse como elemento } \\
\text { vehicular para la } \\
\text { planificación y abordaje de } \\
\text { las transiciones en } \\
\text { educación. }\end{array}$ \\
\hline $\begin{array}{c}\text { Beltrán- } \\
\text { Villamizar et al. } \\
(2015)\end{array}$ & Colombia & $\begin{array}{l}\text { Analizar los avances y } \\
\text { retos en materia de } \\
\text { educación inclusiva en } \\
\text { Colombia, a través de un } \\
\text { análisis comparativo } \\
\text { entre las políticas y } \\
\text { estrategias desarrolladas } \\
\text { en Colombia y España. }\end{array}$ & $\begin{array}{l}\text { Cualitativo - } \\
\text { Comparativo }\end{array}$ & $\begin{array}{l}\text { En materia legislativa y } \\
\text { reconocimiento del } \\
\text { principio de inclusión, las } \\
\text { dos naciones son } \\
\text { coherentes, pero la puesta } \\
\text { en práctica de dichas } \\
\text { orientaciones todavía dista } \\
\text { de ser inclusiva. }\end{array}$ \\
\hline $\begin{array}{l}\text { Gallego et al. } \\
\qquad(2016)\end{array}$ & España & $\begin{array}{l}\text { Analizar el apoyo social } \\
\text { desde la perspectiva } \\
\text { comunitaria que aporta } \\
\text { una visión innovadora } \\
\text { sobre los procesos de } \\
\text { apoyo en el ámbito } \\
\text { educativo }\end{array}$ & $\begin{array}{l}\text { Cualitativo } \\
6 \text { centros } \\
\text { educativos }\end{array}$ & $\begin{array}{c}\text { Se destaca el impacto que } \\
\text { ha supuesto el desarrollo } \\
\text { del proyecto con relación al } \\
\text { abordaje de los problemas } \\
\text { educativos desde una } \\
\text { dinámica colaborativa } \\
\text { favoreciendo el desarrollo } \\
\text { de comunidades } \\
\text { inclusivas. }\end{array}$ \\
\hline
\end{tabular}

Fuente: Elaboración propia 
Tabla 4 (Continuación)

Estudios categoría Institucional

\begin{tabular}{|c|c|c|c|c|}
\hline Autor y Año & País & Objetivo & $\begin{array}{c}\text { Tipo de } \\
\text { investigación } \\
\text { - Población }\end{array}$ & $\begin{array}{c}\text { Conclusiones } \\
\text { principales }\end{array}$ \\
\hline \multicolumn{5}{|c|}{ Evaluación institucional } \\
\hline $\begin{array}{l}\text { García-Cano et } \\
\text { al. (2016) }\end{array}$ & España & $\begin{array}{l}\text { Analizar el proyecto } \\
\text { pedagógico de } \\
\text { Comunidades de } \\
\text { Aprendizaje desde una } \\
\text { mirada intercultural. }\end{array}$ & $\begin{array}{l}\text { Cualitativo } \\
1 \text { institución } \\
\text { educativa }\end{array}$ & $\begin{array}{c}\text { Se evidencia una } \\
\text { transformación del } \\
\text { concepto de diversidad y } \\
\text { diferencia; un cambio de } \\
\text { los procesos de } \\
\text { enseñanza-aprendizaje; un } \\
\text { tránsito de lo individual } \\
\text { hacia lo colectivo a partir } \\
\text { de la restructuración de las } \\
\text { relaciones socio-escolares. }\end{array}$ \\
\hline $\begin{array}{l}\text { Jiménez et al. } \\
\qquad(2017)\end{array}$ & España & $\begin{array}{l}\text { Analizar dos sistemas de } \\
\text { actividad educativa en un } \\
\text { mismo contexto escolar: } \\
\text { procesos de enseñanza- } \\
\text { aprendizaje basados en } \\
\text { enfoques tradicionales y } \\
\text { procesos de enseñanza- } \\
\text { aprendizaje inspirados en } \\
\text { el modelo Quinta } \\
\text { Dimensión (5D). }\end{array}$ & Cualitativo & $\begin{array}{c}\text { Se amplían las } \\
\text { oportunidades de éxito } \\
\text { escolar y se eliminan } \\
\text { barreras para su } \\
\text { aprendizaje y participación } \\
\text { cuando el currículo se } \\
\text { ajusta a la cultura, cuando } \\
\text { hay interacciones } \\
\text { colaborativas, }\end{array}$ \\
\hline $\begin{array}{l}\text { Mateus et al. } \\
(2017)\end{array}$ & Colombia & $\begin{array}{c}\text { Identificar las } \\
\text { percepciones acerca de la } \\
\text { cultura y } \\
\text { las prácticas inclusivas de } \\
\text { una comunidad académica } \\
\text { en un centro educativo } \\
\text { que implementa políticas } \\
\text { de inclusión. }\end{array}$ & $\begin{array}{l}\text { Cuantitativo } \\
71 \text { miembros }\end{array}$ & $\begin{array}{l}\text { Los miembros de la } \\
\text { comunidad tienen } \\
\text { percepciones similares en } \\
\text { torno a la cultura inclusiva } \\
\text { de la institución. Sin } \\
\text { embargo, se identificó que } \\
\text { las percepciones sobre las } \\
\text { prácticas inclusivas en } \\
\text { padres de hijos con } \\
\text { discapacidad las perciben } \\
\text { en una menor proporción. }\end{array}$ \\
\hline \multicolumn{5}{|c|}{ Cuestionarios e instrumentos } \\
\hline $\begin{array}{l}\text { Arnaiz et al. } \\
\quad(2015)\end{array}$ & España & $\begin{array}{l}\text { Validar el instrumento } \\
\text { ACADI (Autoevaluación de } \\
\text { Centros para la Atención a } \\
\text { la Diversidad desde la } \\
\text { Inclusión). }\end{array}$ & Instrumental & $\begin{array}{c}\text { El instrumento presenta } \\
\text { validez de contenido y se } \\
\text { identifica fiabilidad para la } \\
\text { autoevaluación de centros, } \\
\text { generando procesos de } \\
\text { reflexión para la creación } \\
\text { de contextos educativos } \\
\text { inclusivos. }\end{array}$ \\
\hline $\begin{array}{l}\text { Juang et al. } \\
(2016)\end{array}$ & $\begin{array}{l}\text { Estados } \\
\text { Unidos }\end{array}$ & $\begin{array}{l}\text { Poner a prueba un } \\
\text { instrumento de medición } \\
\text { que busca ver cómo los } \\
\text { padres de familia hijos de } \\
\text { inmigrantes de Asia } \\
\text { conviven y manejan la } \\
\text { relación de las dos } \\
\text { culturas con sus hijos } \\
\text { asiático-americanos }\end{array}$ & $\begin{array}{l}\text { Instrumental } \\
575 \text { asiático- } \\
\text { americanos }\end{array}$ & $\begin{array}{l}\text { Los resultados muestran } 7 \\
\text { subescalas confiables y el } \\
\text { instrumento presenta } \\
\text { validez de constructo. }\end{array}$ \\
\hline
\end{tabular}

Fuente: Elaboración propia 


\section{Conclusiones y Discusión}

El objetivo principal de la presente revisión sistemática fue identificar el abordaje que la comunidad académica y científica está dando a la educación inclusiva, para analizarla principalmente a la luz de las investigaciones que se están realizando en diferentes niveles educativos, con estudiantes, docentes, familias y a nivel institucional. La revisión realizada se convierte en un insumo para profundizar en el conocimiento de la educación inclusiva, en su investigación o en la aplicación de estrategias novedosas para mejorar la calidad de la misma y de esta manera, impactar positivamente en los educandos y educadores.

Los resultados evidenciaron que predominan investigaciones cualitativas, seguida de las que contemplan un diseño cuantitativo; fueron muy pocos los estudios que trabajaron posturas mixtas. Se considera que realizar investigaciones con diseño mixto para abordar cualquier variable en el contexto educativo, permitiría dar una perspectiva más amplia del fenómeno y además contaría con un análisis más riguroso y abarcador al integrar datos provenientes de ambas tradiciones de métodos empíricos (Pole, 2009). Esto es una invitación a los actores de los ámbitos educativos, pedagógicos y de orientación, para contemplar el uso de metodologías abarcadoras que permita una mirada holística de la educación inclusiva.

Sería favorable intensificar la investigación en estudiantes desde los primeros años de educación, por ejemplo, en el nivel preescolar y primaria, que son los momentos de inmersión al contexto educativo (Cuevas et al., 2014; Gonzales y Serrano, 2016; Sekkel y Matos, 2014). Intervenir con los estudiantes desde un enfoque diferenciado y diverso en edades tempranas, fortalece una visión del mundo con valores de respeto y aceptación de la diferencia, que permanecerá a lo largo de toda la vida. Además, formar desde la diversidad refuerza las competencias interculturales y de aprender a aprender; esto incluye aspectos motivacionales que involucran a toda la comunidad educativa que, de forma coordinada, colaborativa y conjunta, lograrán formar sujetos responsables, autónomos y comprometidos con los procesos de inclusión social, fundamentados en una educación integral en la academia dentro de los diferentes niveles de formación (Barrios et al., 2016; Gonzales y Serrano; 2016; Rio et al., 2014; Sekkel y Matos, 2014; Zwerg-Villegas y Jiménez; 2015).

Ahora bien, con respecto a las publicaciones centradas en docentes, Bonilla y Jaimes (2017) y Hennig et al. (2018) evidenciaron cómo el profesorado mantiene creencias pesimistas frente a la deserción escolar, debido a que las instituciones no se conciben para los estudiantes como espacios comprensivos frente a sus múltiples necesidades. Por tal razón, como aseguran Moriña y Melero (2016), Vesga et al. (2016), Márquez (2016) y Schwarzenthal et al. (2018), se hace imprescindible que las instituciones y todos los actores que allí coexisten reflexionen sobre sus prácticas discriminantes, ya que no responden a los intereses de los estudiantes y suscitan procesos contradictorios y excluyentes. Teniendo en cuenta lo anterior, aunque los docentes demuestren una percepción positiva hacia la educación inclusiva, se evidencia que algunos docentes siguen teniendo una actitud conservadora, basada en un concepto de educación objetivista en la que definen al alumnado en torno a las necesidades específicas que este presenta y por ende, consideran que este requiere un apoyo educativo especifico por parte de profesionales especialistas (Jiménez-Ruíz et al., 2018), es decir, perciben aún la educación bajo un enfoque rehabilitador y basado en las necesidades y no en las oportunidades que el alumno tiene. En este sentido y como lo señalan Álvarez y López (2015), Flores et al. (2017), Louzada et al. (2015) y Pegalajar y Colmenero (2017), se manifiesta la necesidad de formar a los docentes en temas relacionados con la educación inclusiva, que permita una comprensión clara de su 
concepto, de sus legislaciones y normas, donde se fortalezcan los saberes teóricos y prácticos basados en una realidad educativa diversa.

Así mismo, se necesita capacitar continuamente al docente en estrategias pedagógicas, didácticas, recursos educativos y tecnológicos, con el fin de garantizar una educación de calidad al alcance de todos y todas, y que favorezca la atención integral a los niños, niñas y adolescentes, con el fin de generar unas prácticas educativas, pedagógicas y didácticas donde se generen valores, respeto, lazos socioafectivos, transformadores y de reconocimiento del otro en sus particularidades y como un ser humano en igualdad de derechos.

Por otro lado, es importante formar críticamente a los profesores para que reconstruyan sus prácticas desde el cuestionamiento y la reflexión sobre sus experiencias, llevando así el conocimiento teórico al contraste con los contextos en los que se encuentra inmerso, donde conozca a los estudiantes y a sus familias con las cuales está trabajando, para poder reconocer sus necesidades y potencialidades. Lograr un trabajo articulado con las familias permitirá crear una identidad en el aula y en la escuela, sin discriminación a las familias procedentes de entornos socioeconómicos desfavorecidos, grupos étnicos u otros colectivos en riesgo de exclusión (Vigo et al., 2016).

En cuanto a las políticas institucionales que se han adoptado en pro de alcanzar una educación inclusiva, si bien algunos estudios intentan articular un trabajo en conjunto con los padres de familia (Beltrán et al., 2015; Gallego et al., 2016; Martínez-Figueira et al., 2016), se evidencia que aún es requerida una mayor vinculación de estos en el proceso de educación de sus hijos, como lo mencionan Calvo et al. (2016), su involucramiento podría predecir aún mejor el desempeño y desarrollo de ellos. Así mismo, se requiere de una continua adaptación institucional a los requerimientos y normatividad, pues es un factor clave para lograr una verdadera educación inclusiva (Jiménez et al., 2017).

La revisión sistemática realizada permitió conocer la tendencia en investigación en 4 categorías relacionadas con la población objeto de estudio (estudiantes, docentes, familia, instituciones), sin embargo, es importante mencionar algunas limitaciones en el desarrollo del mismo. Por ejemplo, la búsqueda se realizó con la palabra clave en castellano, lo cual limitó la posibilidad de acceder a publicaciones en otros idiomas. Así mismo, se excluyeron publicaciones de áreas como salud, que seguramente tienen aportes en otros frentes referentes a la temática de análisis.

En síntesis, se permitió observar un mosaico de realidades y de retos pendientes en torno a la inclusión en el contexto educativo, lo cual abre futuras líneas de investigación de relevancia. Por ejemplo, a) se invita a la comunidad científica a intensificar la investigación en los primeros años de educación, que son los momentos de inmersión al contexto educativo (preescolar y primaria); b) profundizar en la formación de docentes y conocer experiencias significativas de prácticas en contextos de aula para lograr la inclusión; c) realizar investigaciones donde la familia sea protagonista y actor fundamental en la articulación con estudiantes, docentes y la comunidad en general, y d) explorar la relación entre los estudiantes con su entorno y, cómo éste influye en su desarrollo, debido a que el ambiente natural es la principal fuente de influencia sobre la conducta, además si las políticas institucionales que regulan la educación inclusiva continúan siendo impuestas y poco contextualizadas, harán que los estudiantes se sientan más excluidos dentro del sistema educativo (Gomes y Souza, 2015; Monarca, 2015); e) a nivel metodológico, se puede optar por estudios con diseños mixtos, longitudinales o cuasi experimentales que permitan seguimientos sistemáticos y confiables en procesos de acompañamiento e intervención; y f) incursionar en investigaciones instrumentales que emprendan procesos de diseño y validación de cuestionarios y herramientas de medición para diferentes poblaciones.

Si bien se ha logrado avanzar en el trabajo oportuno para alcanzar una educación que contempla la diversidad, se hace evidente la necesidad de aunar esfuerzos mediante un trabajo 
mancomunado e interdisciplinar de los diferentes actores de los sistemas académicos y científicos, que bien pueden ser liderados por los orientadores escolares, con el fin de entender la realidad de los estudiantes y su contexto, para así, garantizar su desarrollo integral, su vinculación en el mundo de manera dinámica, constructiva, centrados en el fortalecimiento de habilidades y destrezas, valorando los grandes aportes que realizan a la sociedad.

\section{Referencias bibliográficas}

Acebes-de Pablo, A. y Carabias-Galindo, D. (2016). El alumnado de primaria con Trastorno por Déficit de Atención/Hiperactividad (TDAH): la Musicoterapia como herramienta integradora dentro del contexto del aula de música. Revista Electrónica de LEEME, 38, 1-16. https://ojs.uv.es/index.php/LEEME/article/view/9881/9299

Álvarez Oquendo, R. y Chamorro Benavides, D. (2017), Estrategias didácticas para la incorporación del diseño universal para el aprendizaje en la escuela rural. Panorama, 11(21), 69-81. http://dx.doi.org/10.15765/pnrm.v11i21.1061

Álvarez, P. y López, D. (2015). Atención del profesorado universitario a estudiantes con necesidades educativas específicas. Educ. Educ., 18(2), 193-208. http://doi.org/10.5294/edu.2015.18.2.1

Angenscheidt Bidegain, L. y Navarrete Antola, I. (2017). Actitudes de los docentes acerca de la educación inclusiva. Ciencias Psicológicas, 11(2), 233-243. https://doi.org/10.22235/cp.v11i2.1500

Aquino, S., García, V. y Izquierdo, M. (2014). Tiflotecnología y educación a distancia: propuesta para apoyar la inclusión de estudiantes universitarios con discapacidad visual en asignaturas en línea. Apertura, 6(1), 32-45. https://www.redalyc.org/pdf/688/68831999004.pdf

Arnaiz, P. y Guirao, J. M. (2015). La autoevaluación de centros en España para la atención a la diversidad desde una perspectiva inclusiva: ACADI. Revista Electrónica Interuniversitaria de Formación del Profesorado, 18(1), 45-101. https://doi.org/10.6018/reifop.18.1.214341

Arnaiz, P., de Haro, R. y Guirao, J. M. (2015). La evaluación en educación primaria como punto de partida para el desarrollo de planes de mejora inclusivos en la Región de Murcia. Revista Electrónica Interuniversitaria de Formación del Profesorado, 18(1), 103-122. https://doi.org/10.6018/reifop.18.1.214351

Beltrán, Y., Martínez, Y. y Torrado, O. (2015). Creación de una comunidad de aprendizaje: una experiencia de educación inclusiva en Colombia. Revista Encuentros, 13(2), 57-72. http://dx.doi.org/10.15665/re.v13i2.498

Beltrán-Villamizar, Y. I., Martínez-Fuentes, Y. L. y Vargas-Beltrán, A. S. (2015). El sistema educativo colombiano en el camino hacia la inclusión. Avances y retos. Educ. Educ., 18(1), 62-75. http://doi.org/10.5294/edu.2015.18.1.4

Bonilla, M. E., y Jaimes, S. L. (2017). Parches, pandillas y sistema educativo en Bucaramanga: el reto de la inclusión. Revista Eleuthera, 17, 31-52. http://doi.org.10.17151/eleu.2017.17.3. 
Booth, T. y Ainscow, M. (2015). Guía para la Educación Inclusiva. Desarrollando el aprendizaje y la participación en los centros escolares (adaptación de la tercera edición revisada del Index for Inclusión). OEI, FUHEM. https://www.oei.es/historico/noticias/spip.php?article15212

Bunch, G. (2015). Un análisis del movimiento de la Educación Inclusiva en Canadá. Cómo trabajar. Revista Electrónica Interuniversitaria de Formación del Profesorado, 18(1), 1-15. https://doi.org/10.6018/reifop.18.1.214311

Calvo, M., Verdugo, M. Á. y Amor, A. M. (2016). La participación familiar es un requisito imprescindible para una escuela inclusiva. Revista latinoamericana de educación inclusiva, 10(1), 99-113. http://dx.doi.org/10.4067/S0718-73782016000100006

Cano Barrios, J., Ricardo Barreto, C. y Del Pozo Serrano, F. (2016). Competencia intercultural de estudiantado de educación superior: Un estudio en la Universidad del Norte (Barranquilla. Colombia). Revista Encuentros, 14(2), 159-174. http://dx.doi.org/10.15665/re.v14i2.734

Costa-Renders, E. C (2017). La inclusión de personas con discapacidad: la ecología de los saberes en la universidad. Innovación educativa, 27, 219-234. https://doi.org/10.15304/ie.27.4161

Cuevas, P. G., Romero, C. S. y Guinea, C. L. (2014). The practical application of a technological tool, "reslience tools" for children in context of risk and vulnerability. Procedia - Social and Behavioral Sciences, 116, 3198-3202. https://doi.org/10.1016/j.sbspro.2014.01.734

De la Rosa, L. (2017). Objetos convertidos en sujetos: encuentros con voces excluidas dentro de una asignatura sobre inclusión educativa. Revista electrónica interuniversitaria de formación del profesorado, 20(3), 209-223. https://doi.org/10.6018/reifop.20.3.260111

Flores, V., García, I. y Romero, S. (2017). Prácticas inclusivas en la formación docente en México. Liberabit, 23(1), 39-56. https://doi.org/10.24265/liberabit.2017.v23n1.03

García-Cano Torrico, M., Márquez Lepe, E. y Antolínez Domínguez, I. (2016). Una comunidad de aprendizaje desde el enfoque intercultural: Diálogos, emergencias y contradicciones en la práctica escolar. Educación XX1, 19(2), 251-271. https://doi.org/10.5944/educxx1.16466

Gomes, C. y De Souza, V. L. T. (2015). Os sentidos da inclusão escolar: reflexões na perspectiva da psicologia histórico-cultural a partir de um estudo de caso. Psicologia: teoria e prática, 16(3), 172-183. http://dx.doi.org/10.15348/1980-6906/psicologia.v16n3p172-183

Hernández, M. A., Gomariz, M. A., Parra, J. y García, M. P. (2016). Familia, inmigración y comunicación con el centro escolar: Un estudio comparativo. Educación XX1, 19(2), 127151. https://doi.org/10.5944/educxx1.16457

Hennig, T., Schramm, S. A. y Linderkamp, F. (2018). Cross-informant disagreement on behavioral symptoms in adolescent attention-deficit/hyperactivity disorder and its impact on treatment effects. European Journal of Psychological Assessment, 34(2), 79-86. https://doi.org/10.1027/1015-5759/a000446

Jiménez, F., Lalueza, J. L. y Fardella, K. (2017). Aprendizajes, inclusión y justicia social en entornos educativos multiculturales. Revista Electrónica de Investigación Educativa, 19(3), 10-23. https://doi.org/10.24320/redie.2017.19.3.830

Jiménez Ruíz, M., Rodríguez Navarro, H., Sánchez Fuentes, S. y Rodríguez Medina, J. (2018). Construcción del discurso en torno a la Educación Inclusiva. Revista Electrónica Interuniversitaria de Formación del Profesorado, 21(1), 185-217. https://doi.org/10.6018/reifop.21.1.305771 
Juang, L. P., Shen, Y., Kim, S. Y. y Wang, Y. (2016). Development of an Asian American Parental Racial-Ethnic Socialization Scale. Cultural diversity \& ethnic minority psychology, 22(3), 417431. https://doi.org/10.1037/cdp0000083

Kershner, R. (2016). Including Psychology in Inclusive Pedagogy: ¿Enriching the Dialogue? International Journal of Educational Psychology, 5(2) 112-139. https://doi.org/10.17583/ijep.2016.2109

Louzada, J., Martins, S. y Giroto, C. (2015). Formación de profesores en la perspectiva de la educación inclusiva en Brasil. Revista Mexicana de Investigación Educativa, 20(64), 95-122. http://www.scielo.org.mx/scielo.php?script=sci_arttext\&pid=S1405-66662015000100006

Márquez Vázquez, C. (2016). Factores asociados al fracaso escolar en la educación secundaria de Huelva. REICE. Revista Iberoamericana sobre Calidad, Eficacia y Cambio en Educación, 14(3), 131-144. https://doi.org/10.15366/reice2016.14.3.007

Martínez-Figueira, M. E., Varela Crespo, L. y De Valenzuela, Á. L. (2016). Diversidad y conciliación en Galicia. Un desafío para la educación inclusiva. Revista Prisma Social, 16, 111-155. https://revistaprismasocial.es/article/view/1255

Mateus Cifuentes, L. E., Vallejo Moreno, D., Obando Posada, D., y Fonseca Durán, L. (2017). Percepción de las prácticas y de la cultura inclusiva en una comunidad escolar. Avances en Psicología Latinoamericana, 35(1), 177-191. http://dx.doi.org/10.12804/revistas.urosario.edu.co/apl/a.4854

Ministerio de Educación Nacional MEN (2013). Lineamientos Política de Educación Superior Inclusiva. https://www.mineducacion.gov.co/1759/articles-357277_recurso_0.pdf

Ministerio de Educación Nacional MEN (2017). Decreto 1421 de 2017. Por el cual se reglamenta en el marco de la educación inclusive la atención educativa a personas con discapacidad. http://es.presidencia.gov.co/normativa/normativa/DECRETO\%201421\%20DEL\%2029\%20D E\%20AGOSTO\%20DE\%202017.pdf

Mirón-Canelo, J. A., Iglesias de Sena, H., Alonso Sardón, M., Sánchez Fuentes, S., Fernández Lázaro, C. I., Chamorro Fernández, A. J., Santacruz Ruiz, S., Hernández Galilea, E., Santos García, J. Á., Fernández Martín, C. y Lorenzo-Gómez, M. F. (2019). Educación inclusiva en Medicina: una experiencia formativa sobre personas con discapacidad. Educación Médica, 20(S1), 16-24. https://doi.org/10.1016/j.edumed.2017.07.013

Molina, C. (2004). Concepto de orientación educativa: diversidad y aproximación. Revista Iberoamericana de Educación, 35(1), 1-22.

Monarca, H. (2015). Políticas, prácticas y trayectorias escolares. Perfiles Educativos, 37(147), 1427. https://doi.org/10.22201/iisue.24486167e.2015.147.47259

Moriña, A. y Melero, N. (2016). Redes de apoyo sociales y académicas de estudiantes con discapacidad que contribuyen a su inclusión en la enseñanza superior. Revista Prisma Social, 16, 32-59. https://revistaprismasocial.es/article/view/1252

Muntaner, J. J., Pinya, C. y de la Iglesia, B. (2015). Evaluación de los grupos interactivos desde el paradigma de la educación inclusiva. Revista Electrónica Interuniversitaria de Formación del Profesorado, 18(1), 141-159. https://doi.org/10.6018/reifop.18.1.214371

Nadal Morant, M. J., Grau Rubio, C. y Peirats Chacón, J. (2016). Análisis y valoración del modelo inclusivo en los sistemas de apoyo de centros de infantil y primaria. Educatio Siglo XXI, 34(3), 161-180. http://dx.doi.org/10.6018/j/276001 
Nikleva, D. y Rico-Martín, A. (2017). Attitudes and cultural stereotypes of future teachers towards immigrant students in Spain. [Actitudes y estereotipos culturales de los futuros maestros hacia el alumnado inmigrante en España]. Educación XX1, 20(1), 57-73, https://doi.org/10.5944/educxx1.17491

Núñez del Río, M., Biencinto López, C., Carpintero Molina, E., y García García, M. (2014). Enfoques de atención a la diversidad, estrategias de aprendizaje y motivación en educación secundaria. Perfiles Educativos, 36(145), 65-80. https://doi.org/10.1016/S01852698(14)70638-5

Organización de las Naciones Unidas para la Educación, la Ciencia y la Cultura UNESCO (2009). Directrices sobre políticas de inclusión en la educación. https://unesdoc.unesco.org/ark:/48223/pf0000177849_spa

Organización de las Naciones Unidas para la Educación, la Ciencia y la Cultura UNESCO (2005). Guidelines for Inclusion. Ensuring Access to Education for All. [Orientaciones para la inclusión. Asegurar el acceso a la Educación para Todos]. http://www.ibe.unesco.org/sites/default/files/Guidelines_for_Inclusion_UNESCO_2006.pdf

Palomares-Ruiz, A., Sánchez-Navalón, B. y Garrote-Rojas, D. (2016). Educación inclusiva en contextos inéditos: la implementación de la Pedagogía Hospitalaria. Revista Latinoamericana de Ciencias Sociales, Niñez y Juventud, 14(2), 15071522.doi:10.11600/1692715x.14242240815

Parrilla, Á. y Sierra, S. (2015). Construyendo una investigación inclusiva en torno a las distintas transiciones educativas. Revista Electrónica Interuniversitaria de Formación del Profesorado, 18(1), 161-175. https://doi.org/10.6018/reifop.18.1.214381

Pastor, D. H., Robles, C. P., Robles, D. P., Martínez, M. P. y López, F. R. (2016). Sin rastro de educación inclusiva en la biografía escolar de Raúl: Relato y viñetas elaboradas por un grupo de alumnos. Revista interuniversitaria de formación del profesorado, 87(30.3), 137155. https://dialnet.unirioja.es/servlet/articulo?codigo $=5817761$

Pegalajar, M. del C. y Colmenero, M. de J. (2017). Actitudes y formación docente hacia la inclusión en Educación Secundaria Obligatoria. Revista Electrónica de Investigación Educativa, 19(1), 84-97. http://dx.doi.org/10.24320/redie.2017.19.1.765

Pole, K. (2009). Diseño de metodologías mixtas. Una revisión de las estrategias para combinar metodologías cuantitativas y cualitativas. Renglones, revista arbitrada en ciencias sociales y humanidades, 60, 37-42. https://rei.iteso.mx/bitstream/handle/11117/252/katrhryn_pole.pdf

Powell, S. R., Kearns, D. M. y Driver, M. K. (2016). Exploring the connection between arithmetic and prealgebraic reasoning at first and second grade. Journal of Educational Psychology, 108(7), 943-959. https://doi.org/10.1037/edu0000112

Rojas, A., Domínguez. Y., Torres, L y Pérez, M (2020). El proceso de intervención psicopedagógica en el ámbito educativo. Revista Metropolitana de Ciencias Aplicadas, 3(2), 45-51.

Schwarzenthal, M., Schachner, M. K., van de Vijver, F. J. R. y Juang, L. P. (2018). Equal but different: Effects of equality/inclusion and cultural pluralism on intergroup outcomes in multiethnic classrooms. Cultural Diversity and Ethnic Minority Psychology, 24(2), 260-271. https://doi.org/10.1037/cdp0000173 
Sekkel, M. C. y Matos, L. P. (2014). Educação inclusiva: Formação de atitudes na educação infantil. Psicologia Escolar e Educacional, 18(1), 87-96. https://dx.doi.org/10.1590/S141385572014000100009

Vera Márquez, Á, Palacio Sañudo, J. y Patiño Garzón, L. (2015). Población infantil víctima del conflicto armado en Colombia. Dinámicas de subjetivación e inclusión en un escenario escolar. Perfiles Educativos, 36(145). 12-31 https://doi.org/10.1016/S0185-2698(14)70635-X

Vesga, L., Pisso, L. y Villaquirán, D. (2016). Exclusión escolar: caso de una niña con parálisis cerebral en una institución educativa urbana marginal de Popayán. Revista Katharsis, 21, 217-240. http://revistas.iue.edu.co/index.php/katharsis

Villac, D. (2016) Barreiras e recursos à aprendizagem e à participação de alunos em situação de inclusão. Psicologia USP, 27(3), 492-502. https://doi.org/10.1590/0103-656420140099

Vigo, B., Dieste, B. y Thurtson, A. (2016). Aportaciones de un estudio etnográfico sobre la participación de las familias a la formación crítica del profesorado en una escuela inclusiva. Revista Electrónica Interuniversitaria de Formación del Profesorado, 19(1), 1-14. http://dx.doi.org/10.6018/reifop.19.1.246341

Yupanqui-Concha, A., Aranda Farías, C., Vásquez Oyarzun, C. y Verdugo Huenumán, W. (2014). Educación inclusiva y discapacidad: Su incorporación en la formación profesional de la educación superior. Revista de La Educación Superior, 43(171), 93-115. https://doi.org/10.1016/j.resu.2014.06.003

Zwerg-Villegas, A. y Jiménez., C. (2015). Discriminación socioeconómica en la inserción laboral de graduados universitarios: Percepciones de los decanos de facultades de negocios. Revista mexicana de investigación educativa, 20(64), 71-93. http://www.scielo.org.mx/pdf/rmie/v20n64/v20n64a5.pdf

Fecha de entrada: 24 abril 2019

Fecha de revisión: 30 julio 2020

Fecha de aceptación: 23 septiembre 2020 